\title{
Memory Suggestibility under Social Pressure and Inhibitory Control in Preschoolers
}

\author{
Xiaojun Cao \\ Institute of Education, China West Normal University, Nanchong, China \\ Email: cxj841118@aliyun.com
}

Received 3 March 2015; accepted 24 March 2015; published 27 March 2015

Copyright (c) 2015 by author and Scientific Research Publishing Inc.

This work is licensed under the Creative Commons Attribution International License (CC BY). http://creativecommons.org/licenses/by/4.0/

\section{(c) (i) Open Access}

\begin{abstract}
The current study examined the interaction of inhibitory control and social pressure on young children's memory suggestibility. Children were administered the Video Memory Suggestibility Scale for Children (VMSSC) and batteries of inhibitory control tasks, and were exposed to different levels of situational social pressures during interviews for memory suggestibility. The findings indicated that inhibitory control played a significantly moderating role in the relationship between social pressure and memory suggestibility. The greater the inhibitory control, the lower the effects of social pressure on the memory suggestibility of children. For the children with lower levels of inhibitory control, the social pressure positively predicted memory suggestibility; but for the children with higher levels of inhibitory control, the social pressure didn't significantly predict memory suggestibility. So, to a certain extent, memory suggestibility may be a dynamic integration of stable trait and fluctuating state elements. The implications for the essence of memory suggestibility were discussed.
\end{abstract}

\section{Keywords}

Children, Memory Suggestibility, Inhibitory Control, Social Pressure

\section{Introduction}

Memory suggestibility refers to a person's susceptibility or resistance to misleading information. In the last decade, children's memory suggestibility research has focused more on individual differences that moderate susceptibility to suggestion. Instead of examining the circumstances in which memory suggestibility occurs and age differences in memory suggestibility, individual difference research has been concentrating on the cognitive and 
psychosocial factors that underlie memory suggestibility. Recent research focusing on factors that influence a child eyewitness's memory suggestibility have indicated that cognitive and psychosocial factors may together affect children's responses to suggestive questions [1] [2]. Some endogenous and exogenous factors that have important effects on memory suggestibility were compared in the previous studies. Finnila et al. [3] examined the impact of endogenous and exogenous factors on children's memory suggestibility with BTSS (Endres, 1997), and found that exogenous factors have a greater influence than endogenous factors. Moreover, when children were asked abuse-related questions or interviewed by using social pressured interview techniques, the influence of endogenous factors became insignificant. But to the contrary, some researchers suggested that cognitive factors have a greater impact on memory suggestibility than social factors [2] [4]. Although the interaction of endogenous and exogenous factors on memory suggestibility and memory accuracy is surely existent, the findings just indicated that the interaction of age and exogenous factors on young children's memory suggestibility was significant. It is currently recognized that the effects of cognitive and exogenous factors on the memory suggestibility of children are equally important, but to date, no study has explored the interaction of cognitive and exogenous factors on children's memory suggestibility.

Regarding the cognitive development of children, researchers found that the relation between executive function and memory suggestibility are usually negatively correlated [5]-[7]. Inhibitory control, which refers to an individual's ability to suppress a prepotent response or to inhibit task-irrelevant thoughts on his/her own initiative in order to achieve goals of cognition or behavior, is a central component of executive function [8]. There is evidence that improvement of inhibitory control and consistent individual differences in memory suggestibility all emerge at approximately the same time, that is, between 3 and 5 years of age [9]-[11]. A study has been designed to investigate 51 3- to 7-year-olds' memories about stressful events (inoculation) and the relation between memory suggestibility and inhibitory control, and the results revealed that inhibitory control was a significant predictor of children's memory errors and memory suggestibility [5]. Inhibitory control is likely to cause the irrelevant stimuli to be ignored and to reduce children's sensitivity to interferential stimuli; accordingly, children's memories may be retrieved effectively. Scullin and Bonner (2006) [12] found that the reliability of the Video Suggestibility Scale for Children (VSSC) was affected by children's inhibitory control, and those children whose inhibitory control was significantly developed possessed more stable and consistent memory suggestibility. The individual differences in inhibitory ability predicted children's provision of inaccurate information [13]. Lack of inhibitory control may lead to limited encodings of relevant stimuli, and thus may greatly weaken children's memories of some events, resulting in higher levels of memory suggestibility.

Overall, most of the previous studies supported the conclusion that there was a close relationship between memory suggestibility and inhibitory control, while some results were inconsistent [2]. Researchers used two empirical studies to explain 4-year-old children's individual differences in memory suggestibility, and the findings indicated that there was no significant correlation between children's resistance to misleading questions and their inhibitory control [14]. Melinder et al. [6] found a negative relation between performance on their inhibitory control task and false affirmatives to misleading questions in a sample of 3- to 6-year-old, but noted that about half of the children reached ceiling on the task. In addition, that the inhibitory control tasks were not diverse enough, at times using a single task [12] [15], also resulted in an inconsistent relationship between memory suggestibility and inhibitory control.

Social pressure is one of the most important exogenous factors which influence children's memory suggestibility [12] [16]. Strongly positive or negative feedback was provided after children answered each question in social pressured interviews. Currently, research in this area has mainly involved examining children's memories of details of medical examinations or social pressured situations, through which children's memory suggestibility was analyzed. The previous findings revealed that an individual's high level of arousal was closely related to high memory suggestibility [16]. Levine and Burgess [17] have demonstrated that compared with the children in low-social pressure group, the children in high-social pressure group recalled fewer target events and showed higher memory suggestibility to misleading questions. But there was evidence of the positive role of social pressure in resistance to suggestions [18]. In addition, some results showed that there was no correlation between social pressure and false recall [5]. The extant research has not yet provided a clear conclusion about the influence of social pressure on children's memory suggestibility. We speculated that the different findings probably reflected different or unclear definitions of cognitive abilities. Because the cognitive abilities and social experiences of individuals (either of the same or different ages) are varied, their perceptions and endurance in the face of social pressure will reveal differences in degree. Once an individual's cognitive ability reaches a cer- 
tain level, it may grant immunity to outside pressure. However, when researchers studied the effects of outside pressure, they often wrongly assumed that there was a linear correlation between age and children's perceptions of social pressure, and this ignorance of an individual's real cognitive abilities led to inconsistent results and subjective conclusions.

Dose an intrinsic association exist among children's memory suggestibility, inhibitory control, and social pressure? It is possible that there is an interative effect of inhibitory control and social pressure on memory suggestibility [12]. Karpinski and Scullin [19] suggested that children with executive function deficits may be especially vulnerable to social pressure from an interviewer, and even when controlling for age, children with better executive function were overall less suggestible in social pressured interviews. Our hypothesis was that inhibitory control would play a significant moderating role in the relationship between social pressure and memory suggestibility.

\section{Method}

\subsection{Participants}

A total of ninety-one 3- to 5-year-old, recruited from Experimental Kindergarten in Beibei of Chongqing, participated in the formal study, including thirty-one 3-year-old (16 boys and 15 girls, mean age $=42.38$ months), thirty 4-year-old ( 14 boys and 16 girls, mean age $=55.07$ months), and thirty 5-year-old (13 boys and 17 girls, mean age $=65.43$ months). All children participated only after parental consent had been granted.

\subsection{Materials}

\subsubsection{Language Proficiency}

Because of the low level of language development in 3-year-olds, a language proficiency test was needed to choose the children who could take part in the formal study. A cartoon picture was shown to the child, and then one interviewer pointed the picture and told a short story about the main plot. After that, the interviewer asked the child whether he/she had understood and could repeat the plot. If the child had understood the story correctly and could repeat the plot fluently, he/she was considered as having passed the test.

\subsubsection{Inhibitory Control}

Hand Game. Children were informed that they would play a hand game with the interviewer. The interviewer asked the children to mimic the interviewer's hand motions. That is, when the interviewer held out a palm, the children were also to hold out a palm. Likewise, when the interviewer held out the back of a hand, children were also to hold out the back of a hand in the same way. After the first 2 practice trials, children received feedback (right or wrong). This was followed by 6 test trials without further feedback. Then, the interviewer asked the children to do the opposite motion. That is, when the interviewer held out a palm, the children were to hold out the back of a hand. Likewise, when the interviewer held out the back of a hand, children were to hold out a palm. After the first 2 practice trials, children received feedback (right or wrong). This was followed by 6 test trials without feedback. Scores of the second test trials in which the interviewer asked children to do the opposite motion were recorded. Scoring was as follows: $0=$ incorrect response or changing incorrect response to the correct, $0.5=$ correct response but delayed 3 seconds, and $1=$ immediate correct response. Coder agreement was $100 \%$.

Day/Night. This Stroop-like task is one of the most classic inhibitory control tasks [20] [21] (Gerstadt et al., 1994; Carlson \& Moses, 2001). First of all, the interviewer verified that children associated the sun with day and the moon with night. Then, the interviewer asked the children to say "day" when shown a black card depicting the moon and stars, and to say "night" when shown a white card depicting a yellow sun. During the practice trials, children were shown two sorts of cards. If the children answered incorrectly, the interviewer repeated the rules and if necessary repeated the practice trials no more than 5 times. Subsequently, children received 16 test trials without feedback in random order. Scores were recorded according to children's answers and the time elapsed. Scoring was as follows: $0=$ incorrect response, $0.5=$ correct response but delayed 3 seconds, and $1=$ immediate correct response. The total score ranged from 0 to 16 . Coder agreement was $100 \%$.

Rabbit/Wolf. Similar to the classic Bear/Dragon task [21]-[23], children were required to selectively suppress commanded actions in the Rabbit/Wolf task. To begin with, the interviewer asked children to imitate 10 actions. Then, she introduced two puppets—a "cute rabbit" and a "ferocious wolf" and instructed children to do what the 
rabbit asked them to do but not to follow the wolf's commands. If a child followed the rabbit's commands and ignored the wolf's commands, he/she passed the practice trials. If a child made a mistake on the wolf practice, the interviewer repeated the rules and inquired the child what he/she should do separately when the rabbit or the wolf commanded him/her to do something. The interviewer provided feedback on the child's response in order to clarify the rules of this task. This was followed by 10 test trials ( 5 rabbit trials and 5 wolf trials in random order) in which children were not given feedback. Children were reminded the rules after finishing 5 test trials regardless of performance. The scoring rule for wolf trials was as follows: $0=\mathrm{a}$ full commanded movement, $1=\mathrm{a}$ partial commanded movement, $2=$ a wrong movement, $3=$ no movement. The scores of all wolf trials ranged from 0 to 15. Whereas, the scoring rule for rabbit trials was just the opposite of wolf trials. The scores for all rabbit trials also ranged from 0 to 15 . The total score ranged from 0 to 30 . Coder agreement was $97 \%$.

\subsubsection{Memory Suggestibility}

The memory suggestibility test consisted of a 6-minute and 51-second video of the cartoon Shuke and Beita and of a subsequent interview about the video. The video's plot was interesting and engaging, and had not been seen by the children in this study. The interview contained 16 closed-ended probe questions. Of all these questions, 8 were non-misleading questions, which mainly examined children's memory accuracy, and 8 were misleading questions, which mainly examined children's memory suggestibility. Half the correct answers of the non-misleading questions were "Yes", and half were "No". All the correct answers of the misleading questions were "No". Sixteen questions were administered for two versions distinctively which were counterbalanced across children. The misleading questions in version 1 were designed to be non-misleading questions in version 2; on the contrary, the non-misleading questions in version 1 were designed to be misleading questions in version 2 . The Cronbach's alpha coefficient of the 16 items was 0.84 .

\subsection{Design}

A 3 (Age: 3- vs. 4- vs. 5-year-olds) $\times 2$ (Level of social pressure: High vs. Low) mixed design was used where age varied between-subjects and level of social pressure was within subject variable. Meanwhile, inhibitory control was manipulated as a moderating variable and memory suggestibility was a dependent variable.

\subsection{Procedure}

Before the formal test, a pre-test trial was carried out among other children in the kindergarten. When the formal test started, three children were taken into a quiet room by an experimenter and told that they would watch a cartoon together. In order to prevent children from discussing the cartoon with each other, which would interfere with the attention and understanding of the cartoon, the children were reminded before the experiment started, "Boys and girls, we'll watch an interesting cartoon about a big cat and a small rat, and you are expected to watch carefully and quietly and not to ask any questions until the end of the cartoon...” Then the segment of the cartoon Shuke and Beita was screened by the experimenter, after which the children were asked whether they had seen the cartoon before, and those children who said that they had seen it were excluded.

Then children were tested individually. Three other experimenters took a child separately to a quiet room for the next interview. First of all, the experimenters played the hand game (i.e., one of the inhibitory control tasks) with children and recorded their scores. Regardless of the performance of children, encouragement and praise were given to them. The hand game lasted approximately 2 minutes. Then, the non-misleading and misleading questions about events in the video were asked and social pressured feedback of different levels was provided to children. Specifically, in the low-social pressure feedback situation, children were given negative feedback after half of the questions were asked, independent of whether the child answered correctly or not; and in the highsocial pressure feedback situation, children were given positive feedback after every incorrect answer and negative feedback after every correct answer.

a) Low Social Pressure Feedback: First, children were asked half of the questions (i.e., 4 non-misleading questions and 4 misleading questions), following which children received mild negative feedback (e.g. "You missed a few questions. Let's go through them again and see if you can do better this time."). Children were given a score of 1 (i.e., Yield score) if they responded affirmatively to a misleading question before they received the mild negative feedback from the interviewer. Yield scores ranged from 0 to 4 . Then, the interviewer repeated the questions to examine whether children changed their initial answers. Changes in response from the 
initial non-misleading and misleading questioning were all given a 1 (i.e., Shift score), permitting a possible range of 0 to 8 . Thus, total scores of Yield plus Shift ranged from 0 to 12. A score for total memory suggestibility in this low-social pressure interview was created by (Yield scores + Shift scores)/12.

b) High Social Pressure Feedback: Children were asked the other half of the questions (i.e., 4 non-misleading questions and 4 misleading questions) after the low-social pressure interview. The positive or negative feedback was provided by the interviewer following the child's specific response to each question. For example, when a child responded affirmatively, he/she was praised with positive feedback such as "Good job, you're so helpful!" before the next question was asked. Children were given a score of 1 (i.e., Yield score) if they responded affirmatively to the initial misleading questioning. Yield scores ranged from 0 to 4 . When a child denied that an event had occurred in the video after a question was initially asked, the interviewer told the child that other kids said the event had presented in the video and instructed him/her to think hard again. Then the interviewer repeated the question. If the child changed the initial answer and responded affirmatively, he/she received a score of 1 (i.e., Shift score) and positive feedback (i.e., “Good job!”) from the interviewer, and then the interviewer moved on to the next question. Shift scores ranged from 0 to 8 . If the child responded negatively once more, the interviewer moved on to the next question without feedback. If the child responded to a misleading question affirmatively before feedback was provided, it was not asked again, so there was no possible Shift score for this question. Therefore, total scores of Yield plus Shift ranged from 0 to 8 . A score for total memory suggestibility in this high-social pressure interview was created by (Yield scores + Shift scores) $/ 8$.

After the entire memory suggestibility test, encouragement and praise were given to children regardless of their performances. If a child responded "yes" or "no" to all of the questions during the interview, he/she received a "response bias" test which included two questions (i.e., "Are you sitting on the chair?" "Are you at home now?"). The experimental data was considered invalid and excluded if the child answered "yes" or "no" to both questions.

Following that, some collective games were played to help the children relax, and then the other two inhibitory control tasks (i.e., the "Day/Night" and "Rabbit/Wolf" tasks) were administered by experimenters. The sequence of the two tasks were counterbalanced across subjects. Each child was tested by an interviewer and was recorded by two other experimenters at the same time. At the end of the experiment, all the children received positive feedback and small gifts. The entire experimental process was taped.

\section{Results}

Preliminary analyses indicated that there were no significant sex differences for any of the variables $(\mathrm{p}>0.05)$. Therefore, we did not analyze sex effects further.

Hierarchical regression analyses predicting total memory suggestibility

In order to comprehensively explore the impact of endogenous and exogenous factors on children's memory suggestibility, inhibitory control, social pressure and age were treated as independent variables, while, total memory suggestibility was treated as dependent variable for hierarchical regression analyses.

A multicollinearity test was carried out during the regression analyses. The results showed that the tolerance was beyond 0.77 , the variance inflation factor was below 1.30, and the condition index was below 14.00 for all of the independent variables, which indicated there was no multicollinearity problem among the independent variables. As shown in Table 1, when total memory suggestibility was the dependent variable, social pressure, inhibitory control and age all entered into the regression equation, predicting children's total memory suggestibility, and the total explanatory power was $58 \%$, in which social pressure was an extremely significant positive predictor $(\beta=0.54, \mathrm{p}<0.001)$, explaining $29 \%$ of memory suggestibility variation. Inhibitory control was an extremely significant negative predictor $(\beta=-0.46, \mathrm{p}<0.001)$, explaining $28 \%$ of memory suggestibility variation, and age was also a significant negative predictor $(\beta=-0.13, \mathrm{p}<0.05)$, explaining $1 \%$ of memory suggestibility variation. It was noticeable that the effects of social pressure and inhibitory control on memory suggestibility were much more significant than that of age, and therefore, it was necessary to further investigate the relation of social pressure, inhibitory control and memory suggestibility.

The moderating effects of inhibitory control on the relation between social pressure and memory suggestibility

The current study sought to examine whether or not inhibitory control played a moderating role in the relation between social pressure and memory suggestibility after controlling for age by administering hierarchical regression analyses. 
Table 1. Summary of hierarchical regression analyses predicting total memory suggestibility.

\begin{tabular}{|c|c|c|c|c|c|c|}
\hline Step & Variable & $R^{2}$ & $\triangle R^{2}$ & $\beta$ & $t$ & $F$ \\
\hline \multicolumn{7}{|l|}{ Step 1} \\
\hline & Social pressure & 0.29 & 0.29 & 0.54 & $8.55^{* * *}$ & $73.07^{* * *}$ \\
\hline \multicolumn{7}{|l|}{ Step 2} \\
\hline & Social pressure & & & 0.54 & $10.92^{* * *}$ & \\
\hline & Inhibitory control & $0.0 \%$ & 0.20 & -.53 & $-10.72^{* * *}$ & $11 / .07$ \\
\hline \multicolumn{7}{|l|}{ Step 3} \\
\hline & Social pressure & & & 0.54 & $11.07^{* * *}$ & \\
\hline & Inhibitory control & 0.58 & 0.01 & -0.46 & $-8.37^{* * *}$ & $82.01^{* * *}$ \\
\hline & Age & & & -0.13 & $-2.39^{*}$ & \\
\hline
\end{tabular}

Note: Inhibitory control score was presented by summing $Z$ scores of three inhibitory control tasks (i.e., Hand Game, Day/Night and Rabbit/Wolf). ${ }^{*}$ p $<0.05, \stackrel{* * *}{\mathrm{p}}<0.001$.

In order to control for the effects of age, we performed a three step regression analysis. Step 1, with age alone as a predictor, resulted in a significant model $(\mathrm{p}<0.001)$, with an $\mathrm{R}^{2}$ of 0.15 . Then the addition of social pressure and inhibitory control in Step 2 produced a significant model $(\mathrm{p}<0.001)$, and increased the $\mathrm{R}^{2}$ to 0.58 . Finally, in order to examine the moderating role of inhibitory control, we included an additional variable for the interaction between social pressure and inhibitory control (i.e., the interactive variable) in Step 3, which also resulted in a significant model $(\mathrm{p}<0.001)$, with an $\mathrm{R}^{2}$ increased to 0.70 .

A multicollinearity test was carried out during the regression analyses. The results showed that the tolerance was beyond 0.77 , the variance inflation factor was below 1.30, and the condition index was below 14.20 for all of the independent variables, which indicated there was no multicollinearity problem among the independent, moderating and interactive variables. As shown in Table 2, the results revealed that the interactive variable was a significant predictor for memory suggestibility $(\beta=-0.34, \mathrm{t}=-8.26, \mathrm{p}<0.001)$, that is, the moderating effect of inhibitory control on the relation between social pressure and memory suggestibility was significant. Because the regressive coefficient was below zero, we can see that the influence of social pressure on memory suggestibility gradually diminished as the level of inhibitory control rose.

In order to visually show the moderating effects of inhibitory control on the relationship between social pressure and memory suggestibility, children were divided into a low inhibitory control group (i.e., one standard deviation below the mean) and a high inhibitory control group (i.e., one standard deviation above the mean). This made it possible to indicate the effects of social pressure on memory suggestibility under different levels of inhibitory control.

When the social pressure varied from a low to high level, the memory suggestibility of children in the low inhibitory control group displayed a linear upward trend. Further analyses showed that for the children with poor inhibitory control skills, memory suggestibility was positively predicted by social pressure $(\beta=0.73, \mathrm{t}=7.87$, $\mathrm{p}$ $<0.001$ ); but for the children with good inhibitory control skills, memory suggestibility was not significantly predicted by social pressure $(\beta=0.23, \mathrm{t}=1.64, \mathrm{p}>0.05)$, that is, their memory suggestibility did not change significantly and remained low regardless of the levels of social pressure (Figure 1).

\section{Discussion}

This study examined the interactions between endogenous and exogenous factors by integrating the effects of inhibitory control, age and social pressure on memory suggestibility. Regression analyses indicated that social pressure and inhibitory control were equally important predictors of memory suggestibility. Scullin and Bonner [12] proposed that inhibitory control might affect the consistency of memory suggestibility in different social pressure situations. Children who have poor executive function may be more suggestible in social pressured interviews [19]. Based on previous research, we hypothesized that inhibitory control may be a moderator in predicting memory suggestibility during the social pressured interview, and the effect of inhibitory control on the 
Table 2. Hierarchical regression analyses examining the moderating effect of inhibitory control.

\begin{tabular}{|c|c|c|c|c|c|}
\hline Variable and Step & $R^{2}$ & $\Delta R^{2}$ & $\beta$ & $t$ & $\Delta F$ \\
\hline \multicolumn{6}{|l|}{ Step 1 (Enter) } \\
\hline Age & 0.13 & 0.13 & -0.13 & $-2.81^{* *}$ & $26.04^{* * *}$ \\
\hline \multicolumn{6}{|l|}{ Step 2 (Enter) } \\
\hline Social pressure & & & 0.54 & $12.99^{* * *}$ & \\
\hline Inhibitory control & 0.58 & 0.45 & -0.46 & $-9.82^{* * *}$ & $96.22^{* * *}$ \\
\hline \multicolumn{6}{|l|}{ Step 3 (Enter) } \\
\hline Social pressure $\times$ Inhibitory control & 0.70 & 0.12 & -0.34 & $-8.26^{* * *}$ & $68.27^{* * *}$ \\
\hline
\end{tabular}

Note: The correlative coefficients of the independent variable (social pressure), the moderating variable (inhibitory control) and the interactive variable (social pressure $\times$ inhibitory control) were checked, and the results indicated that the correlative coefficient between the moderating and interactive variables was excessively large $(r=0.95>0.8)$, which made it impossible to affirm whether the interactive variable was a significant and positive predictor. So the independent and moderating variables were each subtracted from their respective means, and the two results were multiplied. ${ }^{* *} \mathrm{p}<$ $0.01,{ }^{* * * *} \mathrm{p}<0.001$.

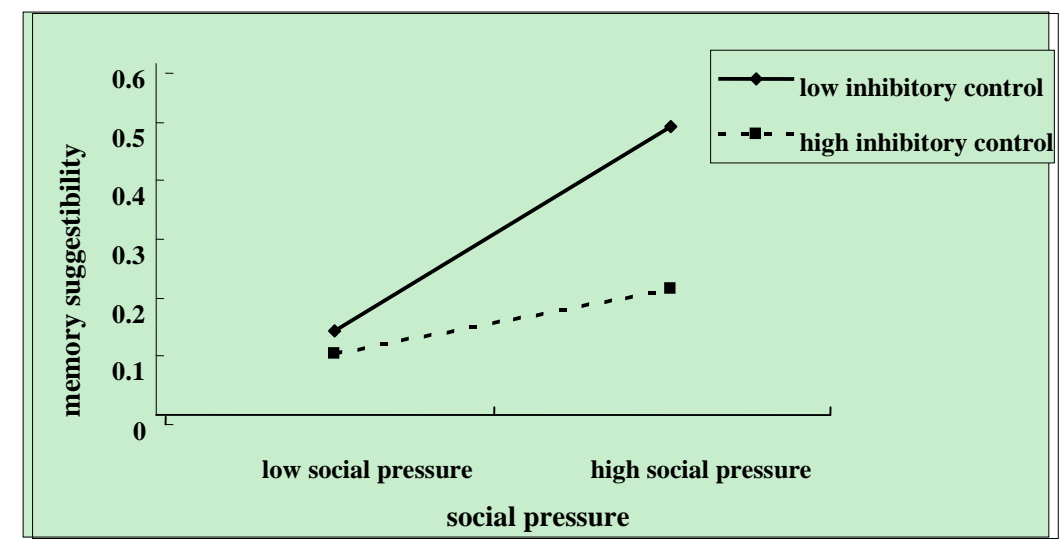

Figure 1. Moderating effects of inhibitory control on the relation between social pressure and memory suggestibility.

relation between social pressure and memory suggestibility was investigated by hierarchical regression analyses which controlled for age. Further analyses demonstrated that for those children with lower levels of inhibitory control, memory suggestibility was positively predicted by social pressure; specifically, those children's memory suggestibility significantly increased in high-social pressure situation, whereas their memory suggestibility significantly decreased in low-social pressure situation. But for those children with higher levels of inhibitory control, memory suggestibility was not significantly predicted by social pressure; that is, whether children received high social pressure or not, their memory suggestibility was not likely to change significantly. Inhibitory control seems to be a protective factor, playing a decisive and protective role in the stability of memory suggestibility.

There are two primary ways to examine memory suggestibility: one is to directly explore the effects of different situations and the other is to explore individual differences. These two methods are generally used separately from each other. Ultimately, the question remains: "Is memory suggestibility a state or a trait?" An individual's memory suggestibility is essentially related to anxiety, intelligence and personality. Individuals with poor cognitive skills, chronic anxiety and introverted character were more suggestible during interviews [24], which seemingly suggested memory suggestibility was a stable individual difference. However, this study concludes that "inhibitory control plays a moderating role in the relation between social pressure and memory suggestibility." This indirectly demonstrates that memory suggestibility should not be simply seen as a state or a trait, because memory suggestibility was affected both by relatively stable internal factors and by variable external factors. Baxter has proposed that the hypothesis that memory suggestibility is a trait neglected to note or 
take into consideration the decisive role that different situations played in bringing out different responses from the same individuals. The memory suggestibility of child witnesses was not only correlated with individuals' traits, but also with the circumstances of the interview [25].

Here, we need a clear understanding of the essence of memory suggestibility. Researchers suggested that memory suggestibility was a structure similar to a trait [26] [27]. Lehman and colleagues (2010) [27] investigated the memory accuracy and memory suggestibility of 4- and 6-year-old in a two-year longitudinal study, and reported that young children's stability of memory suggestibility was very poor across time. Older children's memory suggestibility was more stable than younger children [26]. Therefore, the mechanism of memory suggestibility for different ages may vary. The memory suggestibility of young children hasn't formed a stable trait structure, showing a stative quality, while older children's memory suggestibility gradually transitions from an unstable state to a stable trait. Certainly, further work is needed to explore whether there may be a critical phase during which children's memory suggestibility changes qualitatively. Once memory suggestibility forms a stable trait structure, it's not completely invariable and is likely to be affected by endogenous and exogenous factors from time to time. For example, a child with a low level of inhibitory control tends to be more suggestible than others, but this child will not always be more suggestible. When the child is not affected by external stimuli or the stimulus is small, his/her state of memory suggestibility is not significantly different from a child with a low level of memory suggestibility. However, when external stimuli lead to strong changes in the cognitive or emotional state of this child (e.g., high social pressure leads to tension and anxiety), he/she will tend to be more suggestible than a child with a low level of memory suggestibility. Thus, we speculate that memory suggestibility is a dynamic integration of stable trait and fluctuating state elements. Indeed, this speculation needs validating and fleshing out in further research.

Memory suggestibility is an important research project related to developmental psychology and social psychology. Memory suggestibility research must use cognitive neuroscience to carry out in-depth interdisciplinary research from the three dimensions including development, social cognition and the brain, and to explore the nature and operational mechanism of memory suggestibility for children in different age groups. This study uncovers the interaction between the typical endogenous and exogenous factors on memory suggestibility, and it attempts to ameliorate the defects of earlier studies which partially examined the separate effects of endogenous or exogenous factors. Nevertheless, our current research has just taken a small step in the integrated domain, and further work is needed to classify the various endogenous and exogenous factors, construct rational models, and standardize the research materials.

\section{Acknowledgements}

The authors wish to thank Qing-Ying Liu, Guang Zhao and Xu-Peng Zhao for helpful suggestions. We also express our appreciation to all the investigators for assistance with data collection and coding.

\section{References}

[1] Bruck, M., Ceci, S.J. and Melnyk, L. (1997) External and Internal Sources of Variation in the Creation of False Reports in Children. Learning and Individual Differences, 9, 289-316. http://dx.doi.org/10.1016/S1041-6080(97)90011-X

[2] Bruck, M. and Melnyk, L. (2004) Individual Differences in Children's Suggestibility: A Review and Synthesis. Applied Cognitive Psychology, 18, 947-996. http://dx.doi.org/10.1002/acp.1070

[3] Finnila, K., Mahlberg, N., Santtila, P., Sandnabba, K. and Niemi, P. (2003) Validity of a Test of Children’s Suggestibility for Predicting Responses to Two Interview Situations Differing in Degree of Suggestiveness. Journal of Experimental Child Psychology, 85, 32-49. http://dx.doi.org/10.1016/S0022-0965(03)00025-0

[4] Rothbart, M.K., Ellis, L.K., Rueda, M.R. and Posner, M.I. (2003) Developing Mechanisms of Temperamental Effortful Control. Journal of Personality, 71, 1113-1143. http://dx.doi.org/10.1111/1467-6494.7106009

[5] Alexander, K.W., Goodman, G.S., Schaaf, J.M., Edelstein, R.S., Quas, J.A. and Shaver, P.R. (2002) The Role of Attachment and Cognitive Inhibition in Children's Memory and Suggestibility for a Stressful Event. Journal of Experimental Child Psychology, 83, 262-290. http://dx.doi.org/10.1016/S0022-0965(02)00149-2

[6] Melinder, A., Endestad, T. and Magnussen, S. (2006) Relations between Episodic Memory, Suggestibility, Theory of mind, and Cognitive Inhibition in the Preschool Child. Scandinavian Journal of Psychology, 47, 485-495. http://dx.doi.org/10.1111/j.1467-9450.2006.00542.x

[7] Roberts, K.P. and Powell, M.B. (2005) The Relation between Inhibitory Control and Children’s Eyewitness Memory. 
Applied Cognitive Psychology, 19, 1003-1018. http://dx.doi.org/10.1002/acp.1141

[8] Wei, Y.G., Wu, R.M. and Li, H. (2005) Role of Inhibitory Control in Infants' Executive Function and Theory of Mind. Acta Psychologica Sinica, 37, 598-605.

[9] Perner, J. and Lang, B. (1999) Development of Theory of Mind and Executive Control. Trends in Cognitive Sciences, 9, 337-344. http://dx.doi.org/10.1016/S1364-6613(99)01362-5

[10] Scullin, M.H., Kanaya, T. and Ceci, S.J. (2002) Measurement of Individual Differences in Children’s Suggestibility across Situations. Journal of Experimental Psychology: Applied, 8, 233-246. http://dx.doi.org/10.1037//1076-898X.8.4.233

[11] Zelazo, P.D., Müller, U., Frye, D. and Marcovitch, S. (2003) The Development of Executive Function. Monographs of the Society for Research in Child Development, 68, 1-27. http://dx.doi.org/10.1111/j.0037-976X.2003.00261.x

[12] Scullin, M.H. and Bonner, K. (2006) Theory of Mind, Inhibitory Control, and Preschool-Age Children's Suggestibility in Different Interviewing Contexts. Journal of Experimental Child Psychology, 93, 120-138. http://dx.doi.org/10.1016/j.jecp.2005.09.005

[13] Schaaf, J.M., Alexander, K.W. and Goodman, G.S. (2008) Children's False Memory and True Disclosure in the Face of Repeated Questions. Journal of Experimental Child Psychology, 100, 157-185. http://dx.doi.org/10.1016/j.jecp.2007.09.002

[14] Roebers, C.M. and Schneider, W. (2000) The Impact of Misleading Questions on Eyewitness Memory in Children and Adults. Applied Cognitive Psychology, 14, 509-526. http://dx.doi.org/10.1002/1099-0720(200011/12)14:6<509::AID-ACP668>3.0.CO;2-W

[15] Quas, J.A. and Schaaf, J.M. (2002) Children's Memories of Experienced and Nonexperienced Events Following Repeated Interviews. Journal of Experimental Child Psychology, 83, 304-338. http://dx.doi.org/10.1016/S0022-0965(02)00150-9

[16] Garven, S., Wood, J.M. and Malpass, R.S. (2000) Allegations of Wrongdoing: The Effects of Reinforcement on Children's Mundane and Fantastic Claims. Journal of Applied Psychology, 85, 38-49. http://dx.doi.org/10.1037/0021-9010.85.1.38

[17] Levine, L.J., Burgess, S.L. and Laney, C. (2008) Effects of Discrete Emotions on Young Children's Suggestibility. Developmental Psychology, 44, 681-694. http://dx.doi.org/10.1037/0012-1649.44.3.681

[18] Price, H.L. and Connolly, D.A. (2007) Anxious and Nonanxious Children's Recall of a Repeated or Unique Event. Journal of Experimental Child Psychology, 98, 94-112. http://dx.doi.org/10.1016/j.jecp.2007.05.002

[19] Karpinski, A.C. and Scullin, M.H. (2009) Suggestibility under Pressure: Theory of Mind, Executive Function, and Suggestibility in Preschoolers. Journal of Applied Developmental Psychology, 30, 749-763. http://dx.doi.org/10.1016/j.appdev.2009.05.004

[20] Gerstadt, C.L., Hong, Y.J. and Diamond, A. (1994) The Relationship between Cognition and Action: Performance of Children 3.5-7 Years Old on a Stroop-Like Day-Night Test. Cognition, 53, 129-153. http://dx.doi.org/10.1016/0010-0277(94)90068-X

[21] Carlson, S.M. and Moses, L.J. (2001) Individual Differences in Inhibitory Control and Children’s Theory of Mind. Child Development, 72, 1032-1053. http://dx.doi.org/10.1111/1467-8624.00333

[22] Kochanska, G., Murray, K., Jacques, T.Y., Koenig, A.L. and Vandegeest, K.A. (1996) Inhibitory Control in Young Children and Its Role in Emerging Internalization. Child Development, 67, 490-507. http://dx.doi.org/10.2307/1131828

[23] Carlson, S.M., Moses, L.J. and Claxton, L.J. (2004) Individual Differences in Executive Functioning and Theory of Mind: An Investigation of Inhibitory Control and Planning Ability. Journal of Experimental Child Psychology, 87, 299-319. http://dx.doi.org/10.1016/j.jecp.2004.01.002

[24] Gudjonsson, G.H. (1992) Interrogative Suggestibility: Factor Analysis of the Gudjonsson Suggestibility Scale (GSS 2). Personality and Individual Differences, 13, 479-481. http://dx.doi.org/10.1016/0191-8869(92)90077-3

[25] Ceci, S.J. and Bruck, M. (1993) Suggestibility of the Child Witness: A Historical Review and Synthesis. Psychological Bulletin, 113, 403-439. http://dx.doi.org/10.1037/0033-2909.113.3.403

[26] Roebers, C.M. and Schneider, W. (2002) Stability and Consistency of Children's Event Recall. Cognitive Development, 17, 1085-1103. http://dx.doi.org/10.1016/S0885-2014(02)00075-8

[27] Lehman, E.B., McKinley, M.J., Thompson, D.W., Leonard, A.M., Liebmanm, J.I. and Rothrock, D.D. (2010) LongTerm Stability of Young Children's Eyewitness Accuracy, Suggestibility, and Resistance to Misinformation. Journal of Applied Developmental Psychology, 31, 145-154. http://dx.doi.org/10.1016/j.appdev.2009.11.007 